The Geneva Papers on Risk and Insurance, 19 (No. 73, October 1994) 397-407

\title{
Work and Income in the Third Age - an EU Perspective*
}

\author{
by Alan Walker**
}

\begin{abstract}
The main purpose of this short article is to provide an overview of the key policy issues with regard to the equation that lies at the heart of considerations of the present and future roles of the third age: work and income. Although they are often treated as distinct policy issues work and income, of course, are intertwined - especially as in all industrial societies "work" is invariably defined narrowly as paid employment and, in turn, this is the primary source of income for those of "working age". The third age is a transitional status in which both sides of the work/income equation may be subject to permanent changes and, furthermore, these may result from either individual choice on the part of third-agers or from factors entirely beyond their control. What is certain, however, is that a successful policy towards the third age must take a comprehensive view of both sides of the equation. Therefore, after considering the key issues concerning work and income in the third age, across the EU, I will, in conclusion, address their interrelationship.
\end{abstract}

\section{Work in the third age}

The dominant characteristic of the labour market experiences of third agers is the steady decline in their employment rates. This is an EU-wide phenomenon. Though the rates of decline vary considerably between countries (Table 1). For example between 1971 and 1991 the fall in the employment rate of men aged 60-64 varied from 70 per cent in France and the Netherlands to 26 per cent in Italy and Portugal. This trend is a continuing one among all EU countries and all age groups of men between 55 and 70 . The position of older women is harder to decipher from the statistics but it does appear that a similar decline has taken place and continues to do so. As is well known the main factors behind this development are demand-related. Most importantly for our purposes it should be noted that public policies in the northern EU states have played a significant role in encouraging the trend towards early labour force exit (e.g. Job Release Scheme in UK, VUT in the

* This article is based on a speech to the Carnegie Inquiry to the Third Age Conference "Life, Work and Livelihood in the Third Age", London, 29 April 1993. I would like to acknowledge gratefully the assistance of Geneviève Reday-Mulvey in preparing this paper for publication.

** Professor of Social Policy, University of Sheffield, and Chair of the EU Commission Observatory on Aging and Older People. 


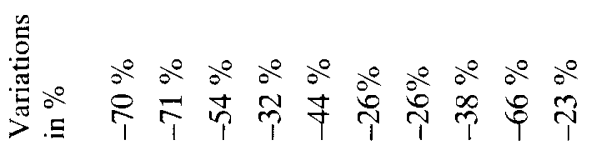

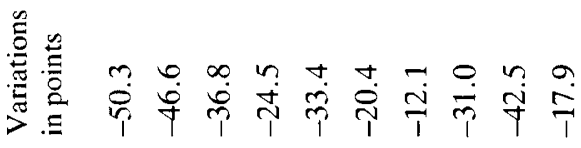

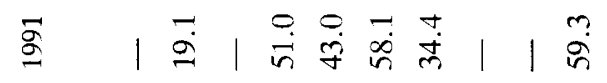

䒺

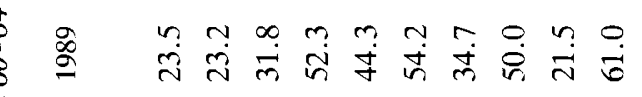

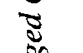

竞站

छ

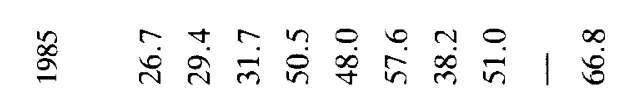

\& m

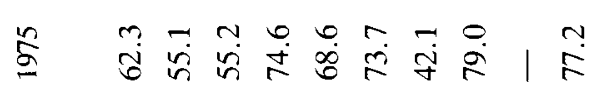

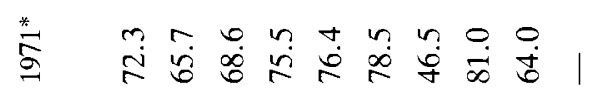

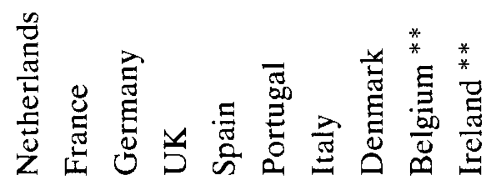

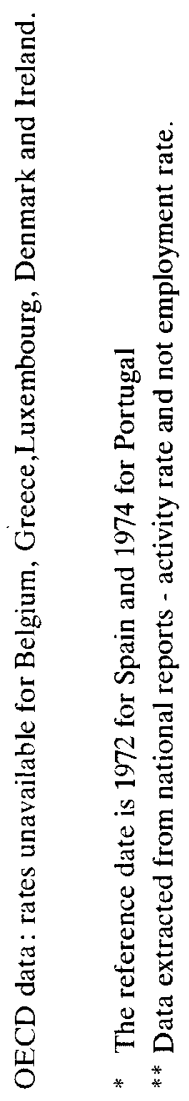


Netherlands, pre-retirement in Denmark and Germany). So it is not the case that the third age has been ignored (by policy makers with regard to the labour market). However the policies have been mainly one-track, with early exit being seen as a solution (to unemployment) rather than a potential problem. This raises a host of important questions concerning the rights of different age-groups to employment - questions that we do not have space to go into. There are three key points to emphasise given this context.

First, the growth of early labour force exit has diminished the role of public pension systems as the key regulators of retirement. In fact it is not changes in retirement ages or pension ages that have been responsible for the trend towards early exit. Instead there are relatively new institutional mechanisms in most countries that govern both labour force exit and the intervening period between exit and the receipt of a pension. In the majority of northern EU states - Germany, Belgium, France, Luxembourg and the Netherlands - the traditional pattern of labour force exit at pension age has become a minority one - and the UK, Denmark and Ireland are coming close to that position too. Only Greece, Portugal and Italy are exceptions to this new reality. The new institutional mechanisms - sometimes taking the form of extensions of existing measures, as in France, Germany and the UK and sometimes via the introduction of special pre-retirement arrangements such as Italy, the Netherlands and Denmark - have been mainly ad hoc developments and, therefore, they have contributed to the precariousness associated with third age status. Moreover, an important policy implication is that the current focus on the raising of retirement age (in Germany, UK, France and Italy) must be seen in very narrow terms as purely cost saving measures. Since retirement/pension ages are no longer the key regulators of labour force exit such measures, on their own, will do little to restore the balance between economic activity and inactivity in the third age. Indeed they may increase the precariousness of older people caught in the "limbo" or twilight zone between leaving employment and entering retirement with a pension.

Second, one important consequence of the unchecked growth of early exit from the labour force has been that it reinforces the devaluation of third age workers in the labour market. (This is one clear exception to the universal economic law that a contraction in supply is associated with an increase in price.) Thus, over the last 15 years, age thresholds have been lowered in line with the provision of access routes to early exit. This has consequences for the ways that employers perceive older workers and, in turn, the chances they offer them for re-employment. Indeed there is a growing body of evidence in different EU countries to show that third agers are frequently discriminated against with regard to job recruitment, promotions and training. Research shows that age is not a good proxy for the ability to work and learn - therefore discrimination is not only unjust but wasteful of economic capacity and potential. The latest EU wide evidence comes from the Eurobarometer surveys conducted in preparation for the 1993 European Year. We asked whether or not older workers are discriminated against with regard to job recruitment and other aspects of employment (the general public were asked rather than just older workers to avoid the accusation of special pleading). A remarkably high proportion (Table 2) four out of five for the EU as a whole - said that such discrimination does exist with regard to recruitment. Some specific figures were: UK 82 per cent, France 82 per cent, Germany 78 per cent, Spain 75 per cent and Portugal 66 per cent. Moreover, there was hardly any difference based on the age of respondents - all age groups believe that discrimination takes place against older workers. 
Table 2:

Proportion believing that older workers are discriminated against in employment

\begin{tabular}{|lcccccccccccccccc|}
\hline & EC12 & Belgium Denmark & France & $\begin{array}{c}\text { West- } \\
\text { Germany }\end{array}$ & $\begin{array}{c}\text { East- } \\
\text { Germany }\end{array}$ & $\begin{array}{c}\text { All } \\
\text { Germany }\end{array}$ & Greace & Ireland & Italy & $\begin{array}{c}\text { Luxem- Nether- } \\
\text { bourg }\end{array}$ & $\begin{array}{c}\text { Ponds } \\
\text { Portugal }\end{array}$ & Spain & UK \\
\hline Recruitment & 78.7 & 82.5 & 80.1 & 81.8 & 76.3 & 82.2 & 77.6 & 76.9 & 74.7 & 77.1 & 82.4 & 83.2 & 66.1 & 74.8 & 82.4 \\
Promotion & 61.5 & 59.9 & 63.6 & 63.3 & 56.1 & 49.6 & 54.7 & 62.3 & 63.3 & 54.7 & 57.5 & 51.8 & 55.9 & 64.6 & 77.7 \\
Training & 67.1 & 68.5 & 64.2 & 68.6 & 63.7 & 62.5 & 63.4 & 64.4 & 69.3 & 63.3 & 66.7 & 65.0 & 64.3 & 64.8 & 77.3 \\
Status & 48.7 & 49.5 & 37.9 & 52.1 & 39.6 & 26.0 & 36.7 & 63.9 & 49.7 & 48.8 & 49.1 & 35.0 & 52.6 & 57.1 & 58.3 \\
\hline
\end{tabular}

Source: Age and Attitudes, Main results from a Eurobarometer Survey, EC, DGV, 1993.

Table 3:

Proportion of the general public who think their government should introduce laws to try to stop age discrimination

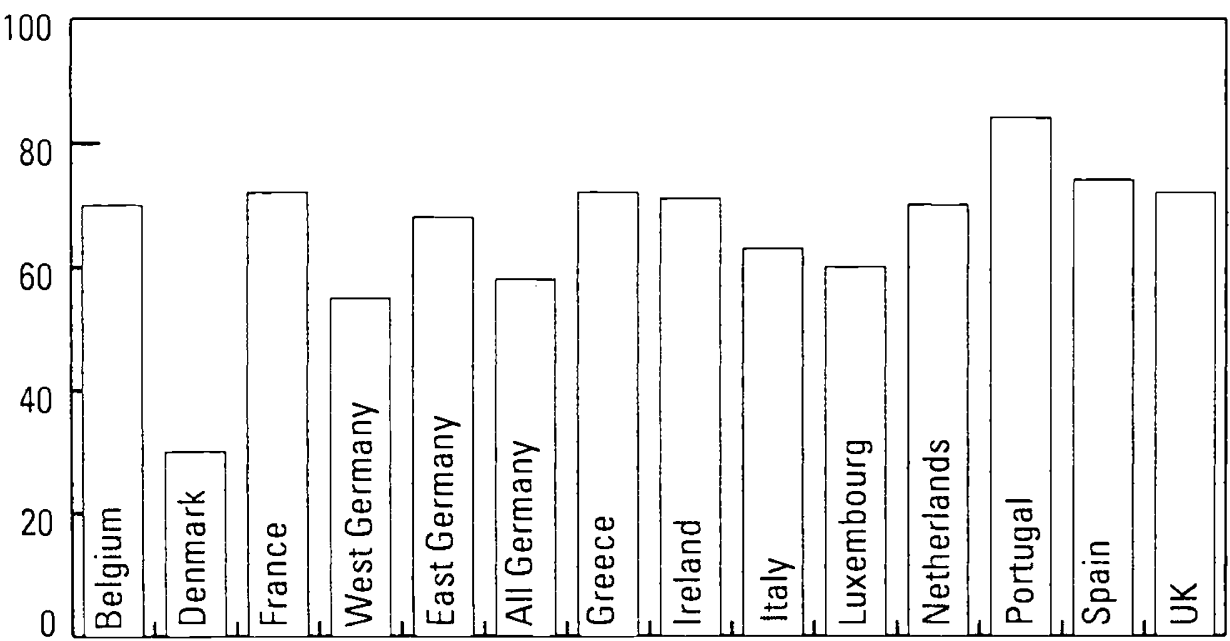

Source: Age and Attitudes, Main results from a Eurobarometer Survey, EC, DGV, 1993.

This begs the question about action to combat age discrimination. According to the Eurobarometer survey, a majority of two to one across the whole EU favoured legislation (of those that expressed an opinion the majority was four to one). Figures are given in Table 3. Denmark is the only country in which the proportion in favour was less than 50 per cent. So far only France and the Netherlands have introduced limited employment protection for older workers and, only in France, can this be said to resemble anti-discrimination legislation - upper age bars on recruitment are forbidden as is redundancy solely on grounds of age - but these measures are not enforced strictly. In 1989 France introduced further measures to encourage employers to retain older workers, e.g. financial penalties on companies for making redundant employees aged 55 and over and increased state contributions to the training of those aged 45 and over. 
There is no easy answer to the question of whether or not to legislate: but it is certain that there will be increasing pressure for such action from pensioner organisations. Also the European Parliament has discussed this issue and my own research in the UK shows that employers themselves are not opposed to legislation. The EU Commission must put its own house in order before it attempts to encourage good practise elsewhere (upper age bars of 35 are still common in recruitment to the Commission).

Third, despite this gloomy scenario, there are signs of change for the better on the part of both EU employers and governments in the EU.

When we addressed the question of age substitution in the Eurobarometer surveys we asked whether or not people in their fifties should give up work to make way for younger ones. Despite rising unemployment and an embedded culture of early exit, the clear majority view was that they should not: two-thirds of the EU as a whole, 69 per cent in the UK, 67 per cent in France, 70 per cent in Germany, 62 per cent in Italy, 75 per cent in the Netherlands, 59 per cent in Spain and 46 per cent in Portugal (see Table 4). Furthermore younger and older people shared the same opinion.

However there is growing evidence that some employers are beginning to take a more enlightened, less stereotypical, view of the third age. This is true particularly in France and the UK and the examples stretch beyond the now well-known cases of special recruitment drives in companies such as B \& Q and Tesco. Indeed major employers such as Renault and Aérospatiale are developing holistic human resource strategies that are concerned with the health as well as the productive efficiency of workers. This implies that a long-term view of training and employee development is necessary as well as specific measures for third agers.

Finally with regard to employment, for obvious reasons EU governments are beginning to shift from the one-dimensional early exit policy of the past 20 years. Examples include the German (not very successful) attempt to encourage gradual rather than early retirement, similarly in France, Denmark and Spain (but none of the partial exit measures have proved popular so far); the French "return to work contracts" for the over fifties and the Belgian flexible pension age.

None of these measures amounts to a clear change in direction but the indications of change are there. What is obvious is that if policies do not take on the comprehensive character required - a mixture of government, employer and employee action - the future of the third agers who cannot freely choose the exit route will be very bleak indeed.

\section{Income in the third age}

Turning to income issues, the dominant source of income for third agers in retirement in all EU countries is public pensions (see Table 5).

The fourth pillar, employment income, plays a relatively small part, though there are considerable variations, as Table 5 shows. At first glance the north-south axis may seem an important source of these variations but data for Greece (not shown because they are not fully comparable) indicate that pensions (public mainly) account for nearly 90 per cent of the income of people aged 60 and over, while wages and salaries make up less than 2 per cent. Moreover in discussions about the future of pension systems, the idea of extending 
Table 4:

People in their 50s should give up work to make way for younger people

\begin{tabular}{|c|c|c|c|c|c|c|c|c|c|c|c|c|c|c|c|}
\hline & $E C 12$ & Belgium & Denmark & France & $\begin{array}{l}\text { Wess- } \\
\text { Germany }\end{array}$ & $\begin{array}{l}\text { East- } \\
\text { Germany }\end{array}$ & $\begin{array}{c}\text { All } \\
\text { Germany }\end{array}$ & Greece & Ireland & Italy & $\begin{array}{l}\text { Luxem- } \\
\text { bourg }\end{array}$ & $\begin{array}{l}\text { Nether- } \\
\text { lands }\end{array}$ & Portugal & Spain & UK \\
\hline Agree strongly & 9.9 & 13.4 & 9.8 & 8.6 & 7.5 & 5.5 & 7,0 & 17.9 & 8.2 & 12.4 & 14.0 & 9.4 & 20.3 & 9.9 & 9.0 \\
\hline Agree slightly & 20.5 & 24.3 & 22.2 & 21.8 & 19.0 & 17.9 & 18.8 & 25.8 & 18.5 & 20.9 & 17.4 & 13.4 & 31.5 & 24.7 & 17.2 \\
\hline Disagree slightly & 33.3 & 37.5 & 25.4 & 36.6 & 40.9 & 39.7 & 40.6 & 26.7 & 26.7 & 30.7 & 31.4 & 33.1 & 20.7 & 34.0 & 25.4 \\
\hline Disagree strongly & 32.3 & 21.5 & 41.9 & $30.1^{\circ}$ & 28.5 & 33.8 & 29.6 & 22.9 & 40.8 & 32.2 & 33.7 & 41.7 & 25.5 & 25.4 & 43.8 \\
\hline $\mathrm{Dk}$ & 4.0 & 3.3 & 0.8 & 2.9 & 4.1 & 3.1 & 3.9 & 6.7 & 5.8 & 3.8 & 3.5 & 2.3 & 2.1 & 5.9 & 4.6 \\
\hline
\end{tabular}

Source: Age and Attitudes, Main results from a Eurobarometer Survey, EC, DGV, 1993.

the portion of the older population that remains economically active, either in full or parttime employment, is a prominent issue and some recent policy developments have begun to reflect this.

For those below the pension age threshold the state has played an increasing role through pre-retirement and early retirement pensions, unemployment, social assistance and disability benefits - as employment income has contracted. Thus, as noted above, there is no special income provision for the third age, those excluded from the labour force against their will exist on a variety of ad hoc arrangements underpinned by social assistance, while waiting for full access to any pension provision they may be entitled to.

There is no clear pattern among EU countries concerning the provision of transitional income but there is when it comes to pension systems.

The first point to emphasise is that there is a clear dividing line between flat rate and earnings-related basic pension schemes - the former as in Denmark, Ireland, the Netherlands and the UK and the latter as in the rest of the EU. In other words Bismarck is more popular than Beveridge. But beyond this apparently straightforward distinction the picture is more complicated: most importantly there is the citizenship pension eligibility criteria in Denmark and the Netherlands and the employment/contribution testing in the other countries. Then there is the pattern of interaction between statutory - first-tier - pensions and supplementary ones. The UK represents the sole case in the EU of a flat-rate basic pension coupled with a compulsory earnings-related one. The most common model couples an earnings-related basic pension with a voluntary supplementary one (Belgium, Germany, Greece, Luxembourg, Portugal and Spain). Of equal interest is the fact that it is the earnings-related pension schemes that have posed the most challenging funding questions among EU countries, yet it was the provider of one of the flat-rate pensions (the UK) that took the first step to curb pension costs.

Secondly, there is wide variation between member states in the success of their pension and wider social protection schemes in promoting economic security in the retired part of the third age. How do we judge success in this context? Well the EU itself has agreed two criteria in the Social Charter (or Chapter). These concern the maintenance of living standards on retirement and protection from poverty and coincide with the criteria that social scientists would normally use to judge the effectiveness of social protection schemes. Thus paragraphs 24 and 25 of the Charter state that: 

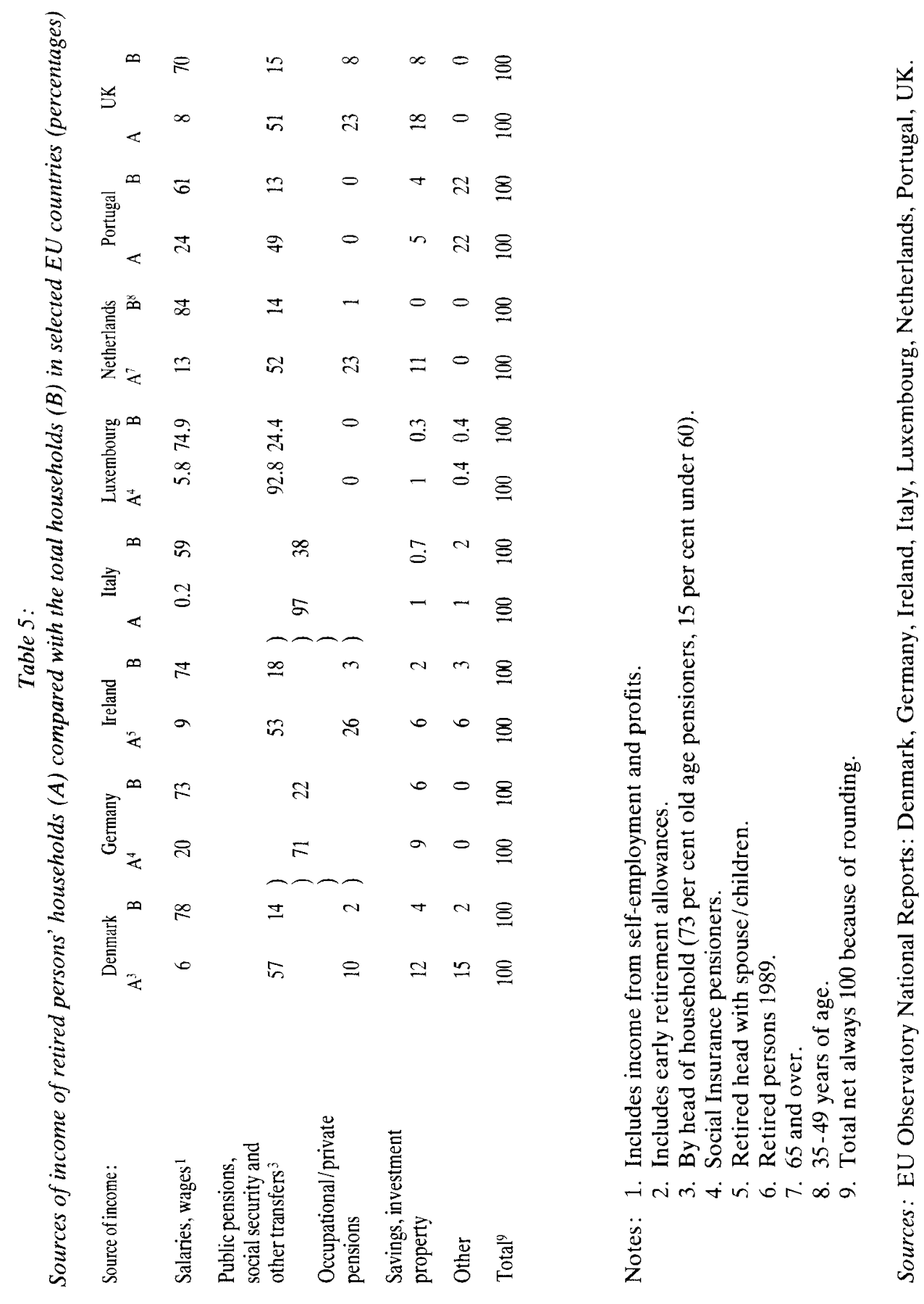
24. Every worker of the European Community must, at the time of retirement, be able to enjoy resources affording him or her a decent standard of living.

25. Every person who has reached retirement age but who is not entitled to a pension or who does not have other means of subsistence must be entitled to sufficient resources and to medical and social assistance specifically suited to his needs.

As far as the maintenance of living standards is concerned there is no doubt that, for those with full labour force careers or credits, the Bismarckian carnings-related schemes produce better rewards than do the Beveridge ones (even when compulsory earnings related pensions are added). As can be seen in Table 6 , replacement ratios for a married man who was on average earnings vary from 88 per cent in Belgium, 83 per cent in France, 69 per cent in Germany to 64 per cent in the UK (the joint lowest). The UK's system performs significantly worse than other flat-rate basic pension schemes. Because of their citizenhip qualifications conditions the schemes in Denmark and the Netherlands and, to some extent, Ireland afford the greatest protection to those who have not built-up a full record of contributions (especially women).

As far as the protection of older people from proverty is concerned EU countries divide into three groups. But before summarising the data it is important to note that proverty is heavily concentrated on the fourth age, especially among women. This is mainly because of the fact that their generation did not retire on as advantageous terms as younger ones (in general the younger the age group of pensioners the higher their income) and their sex does not have the same access to employment-related pensions as men. This does not down-grade the importance of the third age but emphasises the need for a long-term focus on pension provision.

Policy-makers are apt to concentrate on tomorrow's pensioners and, as a consequence, sometimes overlook today's - but someone in the middle of their third age may expect to live for another 20-30 years. It is also important to emphasise the lack of reliable data on the incomes of older people in the majority of EU countries. Thus policy-makers simply do not have access to the information necessary for making informed judgement about social priorities. It is impossible, for example, in most countries to discern the income position of the third age.

Having made these two qualifications such data as there are puts Denmark, Luxembourg, Ireland and Germany (former FDR) in the low poverty rate category (less than 10 per cent); France, the Netherlands and Belgium in the median category (10-13 per cent) and Greece, Spain and Portugal in the high one. The cases of Italy and the UK are difficult ones. Because of regional differences in Italy, the centre-north is in the median range while the south is in the high one. Using the social assistance measure of poverty the UK is in the median category but on the basis of the officially favoured 50 per cent of average income it would be in the high one. In short, even in this small Community of twelve nations there is a huge variation in the relative living standards of older people - the highest national poverty rate is seven times greater than the lowest. Even in the northern area of the EU the poverty rate in the UK is three times that in Germany (old Lander). These differences will be called increasingly into question by pensioners and especially those in the third age.

These objective data are supported by the subjective opinions of older people themselves. Thus when we asked about their financial situation and the adequacy of their pensions 
Table 6:

Net replacement ratios of first and second tier pensions in EU countries $1989^{1}$

\begin{tabular}{|c|c|c|c|c|c|c|}
\hline \multirow{2}{*}{ Number of Years } & \multicolumn{6}{|c|}{ Gross Salary as a Proportion of the Average } \\
\hline & \multicolumn{2}{|c|}{$2 / 3$} & \multicolumn{2}{|c|}{100} & \multicolumn{2}{|c|}{200} \\
\hline Employed: & $35-45$ & 20 & $35-45$ & 20 & $35-45$ & 20 \\
\hline & $\%$ & $\%$ & $\%$ & $\%$ & $\%$ & $\%$ \\
\hline Belgium & 91 & 39 & 88 & 42 & 68 & 43 \\
\hline Denmark & 83 & 82 & 74 & 59 & 72 & 46 \\
\hline France & 94 & 51 & 83 & 46 & 73 & 47 \\
\hline Greece & 132 & 125 & 114 & 84 & 99 & 71 \\
\hline Germany & 66 & 31 & 69 & 33 & 70 & 35 \\
\hline Ireland & 84 & 84 & 64 & 62 & 61 & 36 \\
\hline Italy & 91 & 56 & 92 & 59 & 94 & 57 \\
\hline Luxembourg & 85 & 45 & 76 & 44 & 65 & 39 \\
\hline Netherlands & 90 & 90 & 82 & 67 & 81 & 47 \\
\hline Portugal & 95 & 58 & 98 & 58 & 103 & 59 \\
\hline Spain & 96 & 75 & 98 & 73 & 97 & 71 \\
\hline UK & 73 & 40 & 64 & 34 & 60 & 34 \\
\hline
\end{tabular}

Source: Eurostat

NOTE: The above table is drawn from a comprehensive analysis of replacement ratios conducted by Eurostat. In order to simplify the presentation it is assumed that the pension is for a married man entitled to a basic or first tier pension together with any compulsory supplementary pension. It is further assumed that the supplementary pension contributes a sum equivalent to 50 per cent of the basic pension for a man working between 35 and 45 years and 25 per cent for one working 20 years. Readers requiring a more detailed picture are advised to consult the Eurostat publication.

a clear correlation emerged between the level of the financial security offered by pensions and the degree of contentment of pensioners. Denmark, Luxembourg and the Netherlands arc the countries where something approaching a "culture of financial contentment" may be said to exist among pensioners (the absence of Germany is explained by the averaging of opinion of residents of the former FDR and GDR). It is worth noting, therefore, that those countries in which the debate about the cost of pensions has been most outspoken - France, Germany, Italy and the UK - are not those in which pensioners express the highest levels of contentment with their pensions.

The third and final income issue concerns the recent changes that EU governments have been making to their pension systems. Although the major policy issue, as far as national policy makers are concerned, is undoubtedly cost containment, it is not the only one by any means and, so far at least, the measures taken have fallen far short of the rhetoric in all but one case. 
The countries that have taken definitive action to limit the future growth of pension costs are Germany and the UK - with Denmark, France, Greece and Italy contemplating such a change. However in most cases the changes are modest. The exception is the UK which not only took action to reduce current spending far earlier than the others (1980) but also cut future spending growth more dramatically than any other EU country. In fact, there are more examples of measures being taken to improve pension provision than those to reduce it. For example Belgium, Denmark, Luxembourg, France and Spain have all taken steps recently to improve the position of pensioners. Even in the German case there are some progressive measures accompanying those aimed purely at cost containment - particularly note-worthy is the increase in the pension contribution credits for each child and the introduction of credits for periods of care for frail persons.

Recent years have also seen the expansion of private personal and occupational additional pension schemes and many of the same problems are being echoed in several EU countries. These include the lack of full inflation proofing, the lack of portability and the exclusion of part-time and low-paid workers (usually women).

It is worth noting that, perhaps as a consequence of the debate that has been conducted in several EU countries and especially the negative tone of that debate, there is quite a high level of pessimism among the general public about how far the pensions contract will be honoured in future. For example in France more than three-quarters of the public thought that the pensions contract would be modified adversely - in Belgium, Denmark and the Netherlands three-fifths held this view. Only in Greece and Portugal were there larger proportions expressing optimism than pessimism. There was also quite a high level of uncertainty about the future of the pensions contract. We also found quite a lot of pessimism and uncertainty concerning the future of the welfare state and whether it would continue to grow and support older people - only just over one in three of EU citizens could be described as confident about the future of the welfare state. Moreover it was in those countries with the highest pension levels that pessimism was most widespread.

\section{Conclusions}

This brings me to my conclusions. It is obvious to everyone that questions are being raised about the future costs of ageing populations in most, if not all, EU countries although costs are greatly exaggerated in many cases by discounting the cumulative impact of economic growth. However the issue that does not seem to have been grasped properly is that piecemeal policies are an inadequate response to the many-faceted nature of population ageing, a comprehensive reassessment is what is required.

At the heart of this reassessment must be the roles that older people occupy in the labour market and this focusses attention directly on the third age because it is here that the transitions from middle age to old age and from employment to non-employment take place and it is here that much of the burden of change has fallen. The sorts of policies necessary, work opportunities (both formal and informal); life long training; combating age discrimination and the promotion of good practice - have been spelt out in the report of the Carnegie Inquiry and I will not dwell on them. Instead let me emphasise the opportunity that confronts EU countries; we are at a unique historical juncture - as well as governments seeking ways of limiting the impact of the "senior boomers"; older people themselves, mostly in the third age, are looking for more active roles in society, they are recognising the connection between activity and health, and are seeking a healthier preparation for the fourth age. At 
the same time employers are beginning to reassess the value of older workers and to regret the loss of skills that early exit entails. So there seems to be a coincidence of interest in the development of a major new initiative to extend the choices open to third agers, a rebuilding of the fourth pillar of retirement income via the encouragement of more flexible relationship between employment and retirement. If we miss this opportunity it may not come again, at least not in the same context of potential consensus as exists at present. It is time for the policy makers to face up to what is now one of the most important challenges confronting all EU countries.

\section{REFERENCES}

WALKER, A., ALBER, J. and GUILLEMARD, A.-M.: Older people in Europe: Social and Economic Policies, the 1993 Report of the European Observatory, Commission of the European Communities, DGV, Brussels.

WALKER, A.: Age and Attitudes, Main results from a Eurobarometer Survey, Commission of the European Communities, DGV, Brussels, 1993.

The Carnegie Inquiry into the Third Age, Life, Work and Livelihood in the Third Age, Final Report, London, 1993. 